\title{
DERECHO PARAGUAYO Y FILOSOFIA DEL DERECHO
}

\author{
Von Alejandro Marin Iglesias
}

Las leyes, con el transcurso del tiempo, crean una trama intrincada en el orden del Derecho, a la voz de las necesidades comunes. Esta trama debe ser objeto permanente de atención de todos los miembros de la comunidad y, muy particularmente, de quienes estudian el proceso de nuestro desenvolvimiento jurídico. Así se alcanzará a conocer mejor la naturaleza de nuestro Derecho y su técnica, lo cual ayudará a la solución de los problemas contemporáneos y futuros.

El Derecho es de interés universal, por la expresiva índole de civilización que contiene. Los hombres en un nivel cultural determinado, buscan el Derecho y requieren necesariamente su vigencia por su condición de instrumento incomparable contra el despotismo o la tiranía, contra el desorden y la anarquía. Solo en un régimen de Derecho, hay defensa para la libertad y el orden.

Nuestro Derecho es de variada y compleja estirpe, pero su evolución solo es posible juzgarla mediante una comprensión cabal de su pasado. Nuestro sistema jurídico, pese a su aparente discontinuidad, of rece una perspectiva histórica uniforme, solo explicable mediante la interpretación de tan numerosos como complejos hechos sociales y culturales. Tiene su período tradicional o histórico, que cubrió un largo lapso de vida peninsular y colonial, al cual siguieron etapas tales como el "formativo", el "transformativo" y el "revolucionario".

Es obvio, quizá, señalar que la estructura jurídica paraguaya pertenece tanto en lo histórico como en lo positivo vigente, a los sistemas de Occidente. La Edad Media europea y más precisamente, las Españas de los siglos VIII al X, dieron los primeros Fueros Reales que basamentaron a las originarias instituciones tanto del derecho público como del privado. En aquella época, plena de hechos notables en el mundo de la península, la Cristianidad había contribuido a iniciar un gran movimiento de sentido jurídico-institucional en los reinos y feudos, en las casas solares y monasterios e iglesias, que dieron lugar a concresiones tan portentosas como las Partidas.

Los primitivos sistemas se habían transformado, y de su índole vernácula y limitada a dictados procesales de leyes no escritas o consuetudinarias, se transfirieron a otros planos mas avanzados. Se observa, pues, que con el correr de las edades, el derecho romano muy especialmente, y las grandes corrientes del pensamiento filosófico greco-judeo-cristiano, habían de provocar reales cambios y crear nuevas estructuras, diversos sistemas, pero siempre partiendo de las mismas múltiples fuentes.

Los reinos peninsulares de la época, con la rica gama de su doctrina y sus instituciones, prepararon para las tierras que en el siglo XV serían descubiertas incorporadas como posesiones ultramarinas a la corona castellana-aragonesa, los pilares de un derecho que coadyuvó a consolidar el patrimonio territorial. Libres más tarde, estos estados no abandonaron el patrimonio legal común. Este fué un aspecto esencial, aunque olvidado, de como la influencia jurídica ibérica contribuyó a fortalecer la obra de la civilización occidental en nuestro hemisferio.

Los antecedentes occidentales en los siglos $\mathrm{X}$ al XV, todos peninsulares, no podían dar lógicamente, una luz definida sobre lo que sería un derecho americano. No fué la ingente obra preparatoria de esos siglos, la que dió esquemas precisos para un futuro Derecho. Empero, en las recopilaciones y los cuerpos orgánicos de las respectivas leyes nuevas, ya se registraron principios, conceptos, instituciones, figuras y procedimientos que, hasta nuestro tiempo, tienen vigencia. 
La paternidad mediata, en consecuencia, de nuestro derecho reside en el edificio jurídico castellano, en los fueros leoneses, burgaleses, aragoneses, navarros, gallegos, etc., y en aquellos códigos, que mediante la trasculturación jurídica, surgieron en Valencia, Granada u otros reinos y califatos levantinos.

De éstos y del romanismo-germanismo, básicamente, se aprovecharon y adaptaron elementos positivos que constituyen concepciones de fondo y forma, verdadero patrimonio de todo el Cristianismo.

$\mathrm{Al}$ contrario de lo que sucedió con los derechos inglés y norteamericano, el derecho peninsular en relación al nuevo de las colonias de las Indias Occidentales, fue cerrando los cauces de la equidad. La rigidez y la severidad de los tribunales del Reino, contribuyeron a dar esta pauta definidamente unitaria. En Inglaterra y las colonias del Norte, subsistieron las dos vías de la equidad y del derecho común, aunque la justicia era administrada por los mismos jueces. "Sin embargo" - dice un jurado norteamericano - "los dos sistemas siguen siendo distintos en la mente de los juristas y magistrados".

La autoridad del Rey fué consolidándose en los siglos que promediaron entre el $\mathrm{X}$ y el XVIII. Fué una conocida lucha secular que pasó por diversas y variadas etapas. Su centralización política y la unificación jurídica que fueron sus características, dieron al Monarca oportunidad de establecer mayores progresos en el orden legal. En la península, el derecho tradicional se bifurcaba entre tanto, ante el cuadro de las originalidades y las necesidades de las Indias americanos. Un vasto complejo de leyes, reglamentos y ordenanzas y, un intrincado sistema judicial, fue creándose con el tiempo.

Había un concepto muy importante que se trasladó a las colonias; la necesidad del Derecho y de su supremacía. Este provenía de la tradición más pura de Castilla y demás antiguos reinos peninsulares. Pero, las leyes de Indias y la justicia castellana en las Américas, tomaron en diversos aspectos diferentes fisonomías. El derecho español mal se adaptaba, a veces, a los nuevos países: problemas sobre la relación o vínculos familiares, privilegios personales, la propiedad, las obligaciones, fueros y clases, desigualdad ante las leyes y las oportunidades. Las nuevas condiciones exigían adaptaciones, salvando las omisiones de las leyes metropolitanas.

Indudablemente, que este problema de la aplicación exclusiva de ciertas leyes del Reino a los peninsulares y otras que se aplicaban a los nativos sin adaptarlas a las nuevas condiciones, fueron aspectos importantes de la gran corriente liberadora que alimentó secretamente los movimientos emancipadores. Habían leyes que carecían de sentido en estos vastos paises y, por consiguiente, un derecho alejado de toda realidad social y política pugnaba por su primacía. Fué necesario, sin embargo, hacer lugar a arbitrios adecuados para ajustar las leyes y, así dar vida al naciente derecho americano.

La igualdad de oportunidades para metropolitanos y nativos, la libre iniciativa para legislar y hacer justicia, los mismos derechos legales para españoles y americanos, fueron fórmulas connotadas de las revoluciones. No buscaron, acaso, en los comienzos y a la manera de su tiempo ser españoles-americanos, o libres, nuestros antepasados al reclamar los derechos de los metropolitanos?. Numerosos fueron los nuevos valores que obligaban a las reformas.

La libertad de acción era, sin embargo, reducida y la iniciativa limitada. En el Paraguay, el derecho español se vivía a travez de la Administración y de pocos organismos judiciales, por nuestra dependencia de Lima, Charcas y Buenos Aires, sucesivamente. 
Empero, este núcleo de instituciones, aunque reducido, trasfundió al cuerpo social un cúmulo de doctrinas jurídicas, suficiente para caracterizar a la nación paraguaya en esta faz de su evolución histórica. Un "Poder Judicial", diríamos, escindido hasta por las distancias geográficas, de sus otras partes vitales, marcó una continuidad leve pero certera. Las características de la Monarquía española no alentaban, pero en las antiguas capas subyacían ideas que competían con el conservatismo peninsular y el absolutismo monárquico. Nuestros letrados conocían la "Ilustración", y leían pública o secretamente a Vitoria, Suárez y Soto, el "Contrato Social”, obras científicas y la esencia del pensamiento de Rousseau y de Voltaire. Y esta espice de "Poder Judicial", representado por el Cabildo y el gremio reducido de los letrados que ejercieron la Abogacía, influyeron y ayudaron a crear una doctrina y un derecho.

La documentación de estas décadas grávidas de acontecimientos futuros registra numerosos "casos" planteados ante Cabildos y regidores sobre mejores derechos en el campo privado, y así tambien en cuanto se referían a derechos de los súbditos contra los excesos del poder virreinal, del gobernador, de los oficiales reales o de otros funcionarios. Los grandes pasos están marcados por ordenanzas como las de Irala, Ramírez de Velazco y Alfaro, en distintos y complejos problemas sociales y jurídicos.

El siglo XIX, aún con sus avatares, fué un período en que se afirmaron derecho y libertades civiles. En el primer cuarto de siglo, ya se observaron cambios sustanciales: mayor flexibilidad y, muy particularmente, afirmatividad en los derechos y libertades. En este momento de la Revolución, sin duda, el derecho paraguayo adquirió su forma única, como sistema unitario y se delineó su futura conformación que tomaría despues fisonomía definitiva.

El pensamiento franciano, por ejemplo, era liberal, tal como lo concibió en su "Estado republicano", pero su idea del derecho era limitada, sujeta a un manejo individualísimo, personal y arbitrario. Era él mismo (Francia) un árbitro de equidad y hacía justicia sujeto a una ley natural racionalista interpretada a un estilo propio. Introdujo profundos cambios, sometidos a una ideología liberal suigeneris, en la propia legislación tradicional, pero plagados de contradicciones.

Las leyes españolas, que mantuvieron su fuerte influencia al advenimiento de la independencia política, habían dado lugar hasta entonces, a pocas interpretaciones variadas y novedosas de los casos americanos. Aquel hermetismo o rigidez de los tribunales y por tanto del derecho, fué roto y se adaptó este orden jurídico a una vasta reintegración de las leyes. Las primeras décadas del siglo XIX fueron pues, de reinterpretación del derecho, lo cual implicaba una revisión parcial y, a veces absoluta, de los fallos anteriores en casos análogos, o la no sujeción a la doctrina de los precedentes judiciales. Este es el significado profundo de las sentencias o resoluciones judiciales del período revolucionario y de la época franciana, que no debe confundirse equívocamente con el problema político. Este fué liberal en el siglo XIX, pese a numerosas actitudes desviadas de las administraciones históricas. Había siempre un sentimiento nacional, proclive al liberalismo en el derecho público, y tradicionalista en lo privado. Lo importante, en realidad, sería que, con la verificación de las mudanzas sociales y la creación de fórmulas nuevas, que aún subyacían a la espera de emerger oportunamente, se elaboraban nuevos valores jurídicos.

Había que afirmar que la era formativa del derecho paraguayo está marcada por un amplio lapso de más de sesenta años. El empirismo que predominó en el período 1840-70, trazó fórmulas e ideó procedimientos para realizar la justicia y hacer el 
derecho. Jueces, Tribunales, Abogados y las leyes españolas antíguas y nuevas ordenanzas genuinas, configuraron y actualizaron los conceptos legales en ciertos órdenes. Se había salido en 1840 de un periplo de violencia y absolutismo y, las ideas básicas del derecho paraguayo tendrían mejor desarrollo al liberarse definitivamente de la ineficiencia y de las trabas de la arbitrariedad. Las bases tradicionales de las Partidas y las Recopilaciones y, las nuevas, contenidas en los modernos códigos españoles, contribuyeron a dar mayor uso eficiente del derecho para lo venidero.

Es obvio señalar, las repercusiones de la guerra de la Triple Alianza en nuestro derecho. El año de 1870, marca indudablemente el comienzo de la era transformativa, en la cual se establecieron muchos valores importantes del sistema jurídico paraguayo.

Los cambios institucionales y políticos, sociales y económicos que, radicalmente, se proyectaron sobre la nación a partir de 1870, influyeron ampliamente sobre nuestro derecho. La sociedad, predominantemente rural, acusó en estos cien años tendencias acentuadas hacia la ciudad y las comunidades aglutinadas en los núcleos urbanos. La aparición de la Judicatura y la Universidad, los cambios en el derecho público, la instauración de un comercio ultramarino y continental, la apertura del país a mercados nuevos, las comunicaciones en desarrollos, el progreso cultural, el derecho del trabajo, los derechos políticos y civiles de la mujer, etc., nos dan en la actualidad la cuantía de las mudanzas sociales y, en consecuencia, de la transformación progresiva y forzosa de nuestro derecho.

La recepción del derecho argentino y por su medio, del romano, del francés y del brasileño, la influencia de la función creadora y permanente del Poder Judicial, la profesión legal y la labor jurisprudencial, fueron factores que dieron en esta era al derecho paraguayo sistematización, racionalidad y amplitud sin precedentes.

El periplo casi centenario de la era transformativa, experimentó modificaciones fundamentales en ciertos campos del derecho. En el privado, empero, se ha mantenido la línea de la continuidad, hasta brindarnos hoy una larga perspectiva histórica de poco más de diez siglos: los conceptos básicos del derecho civil se han delineado con más claridad y firmeza, los derechos individuales tienen mayor vigencia y realidad en la vida de la nación, de modo a constituir un motivo primordial de exigencia popular.

La reforma constitucional del año 1940 marcó una nueva fase histórica. Nunca puede ser un hecho baladí una modificación tan importante como la relacionada con la ley fundamental. En la perspectiva de la vida jurídica nacional, este evento señaló el comienzo de la era revolucionaria de nuestro derecho. Su caracterización se revela en la índole eminentemente social de su contenido y la afectación o limitación de la regulación legislativa por un mayor fortalecimiento de la autoridad administrativa. Un mayor énfasis en la necesidad del "estado administrativo", realizador de la "justicia social", sin necesidad de apelar a categorías jurídicas tradicionales o a procedimientos ya establecidos en el cuerpo jurídico de la nación, entrañaba esta reforma que creó nuevos valores jurídicos: los conceptos contenidos en la legislación social, que desarrollan los derechos sociales; la tradición de la libertad y del orden íntimamente asociados para dar vigencia a una paz aplicada al progreso de la comunidad, y los derechos individuales ajustadamente encauzados para servir los intereses del bienestar general.

Es evidente que el derecho se desarrolló en nuevos planos diferentes de los tradicionales: en lo administrativo y en lo tributario; en el laboral y la seguridad social; en el orden del derecho financiero, la "ciencia política", la seguridad pública y los 
derechos de la ciudadanía; los nuevos derechos del transporte y la espectativa de un nuevo derecho de la electricidad, entre otros aspectos. Pero, siempre se ha visto que el estímulo a lograr una mayor conciencia jurídica del pueblo sería un acentuado beneficio para la protección de los ciudadanos contra los abusos de los funcionarios y una revitalización de la tradición jurídica. La experiencia histórica ya enriquecida en más de un aspecto, es un valor asequible para cumplir fielmente estos objetivos, y su aplicación siempre debe ser requerida.

Los problemas del presente y del futuro han de ser resueltos, pues, al igual que mediante otros resortes, en virtud de la salud del derecho paraguayo de hoy tanto mas que ha sido enriquecida con la promulgación de la nueva Constitución Nacional (1967) y la reforma de la codificación. Se vive, pues, una nueva experiencia jurídica que influirá, sin duda, a una adecuación de la ley a las condiciones cambiantes de nuestra vida social, abonada por la rica experiencia pasada.

El desarrollo de una filosofía del derecho "paraguayo" fué posible determinar con mayor claridad, cuando tomó caracteres concretos en el lapso comprendido por el siglo XIX. Como acontece en todas las naciones, en el Paraguay se profesa una vasta diversidad filosófica jurídica. Sin unidad, estas corrientes provocan contradicciones, aunque están caracterizadas por la coincidencia o coherente relación con lo que en este campo se ha escrito en el continente o en el mundo del derecho del hemisferio occidental.

En una revista esquemática inicial, diremos que el derecho natural, tan divulgado en Occidente, constituye una fuente en que se nutre mas de un aspecto de nuestro derecho. Es un legado de la Edad Media cristiana y quienes lo aceptan esencialmente, aprueban sus alcances en cuanto se refiere a las normas y decisiones legales que están regidas inicialmente por la razón inmutable de Dios y la moral.

El positivismo jurídico, igualmente, no dejó de tener adeptos al establecer que existen profundas diferencias entre ley y moral y, fundamentalmente, señala que la ley constituye una creación cierta del poder político del Estado, poseedor de la autoridad y voluntad mas plenas. La jurisprudencia histórica, particularmente en derecho público ha sido, asímismo, una fuente de atracción basada en la conocida fórmula de que el Derecho es un resultado del desarrollo histórico del espíritu y carácter de un pueblo.

Las modernas versiones de las corrientes tradicionales del pensamiento jurídico, han sido acogidas entusiastamente, tal como acontece con la jurisprudencia sociológica, que aunque muy excepcionalmente, se la ha adoptado para interpretar el derecho como basado en un equilibrio de los variados intereses o como una apreciación de los efectos sociales de diferentes sistemas. El realismo legal, finalmente, tuvo y tiene, fuerte influencia, de modo que las decisiones legales se inspiran en los aspectos económicos, sociológicos o ideológicos que mayor relieve tienen en la sociedad.

Las filosofías del derecho enunciadas han regido algunas expresiones jurídicas nacionales dejando su impronta en más de una página de nuestra historia jurídica. Las distintas teorías del derecho se registran explícita o implícitamente en numerosas instituciones y prácticas jurídicas nacionales. No puede dudarse que, en muchos órdenes, el pensamiento jurídico se inspira en la ley natural; así como es evidente, al igual, que el positivismo ejerce un fuerte influjo, que la jurisprudencia histórica ha pugnado por mantener su hálito y que la filosofía jurídica, en su vasta gama de doctrinas, ha sido factor definidor en numerosos conceptos, categorías y construcciones. 
El aporte de todas y cada una de estas escuelas de filosofía jurídica, ha sido y es hasta hoy valiosa. Las abstracciones son inconciliables, tal vez, pero no crean nuevos imposibles de superar en el ancho proceso del desenvolvimiento cotidiano de nuestra vida social. Y en ello está la verdad, mediante el tiempo y la oportunidad.

En nuestra historia, en los siglos XVIII y parte del XIX no se abandonaron principios tales como el "derecho moral", el "derecho superior", y hasta en cierta agitada época del setecientos, los "derechos del común", supremos y acatables por cabildos y jueces, tribunales y funcionarios administrativos, tanto más porque debían hallarse por encima de leyes positivas, decretos reales y costumbres. Posiblemente, hubo un influjo de maestros europeos tales como Santo Tomás, Suárez o Grocio y Pufendorf, pues no corrian sino los dogmas como esencia básica de la ley que sería interpretada y aplicada.

Eran amplios estos principios de justicia moral. Los conceptos elaborados en este período se trasladaron a nuestro tiempo independiente, a travez de esas ideas agregadas a las cuales corrían las bases del "contrato social". Algunas declaraciones se encuentran en documentos de los primeros veinticinco años, pero ya en nuestra era independiente. Las Constituciones del siglo XIX las generalizan, particularmente la de 1870. No puede negarse el alcance de derecho natural a garantías tales como: respeto a la vida, a la libertad, a la propiedad. Un principio fundamentalísimo o, llamémoslo "garantía", es el del proceso previo al hecho, e igualmente, de que nadie puede ser privado de sus bienes, de sus libertades, etc.

Los principios generales del Derecho están imbuidos de este profundo sentido jusnaturalista cristiano, y figuran en las Constituciones paraguayas. La justicia y la equidad, la libertad y la igualdad aparecen en las leyes, con más énfasis, con mayor difusión y máxima generosidad a partir de 1870. Los principios de derecho natural, rigen con expresiva singularidad en el largo lapso de los gobiernos dictatoriales, si bien su aplicación u observancia fueron lamentablemente enervados o violados por diversas circunstancias. Estos factores circunstanciales someterían, tal vez, a la prueba de la conciencia hechos numerosos, que exigían una aplicación de leyes y disposiciones gubernamentales por quienes administraban justicia con mayor o menor grado de discrecionalidad o arbitrariedad. De estos autos no salieron muy airosos aquellos principios o tan puros pensamientos como la justicia y la rectitud. Ya había una suerte de sistema de justicia política que se acentuaría en ciertos períodos de nuestra historia jurídica con nefastos resultados.

Es meridianamente claro cuanto la actual Constitución garantiza tanto como la estatuyeron las dos anteriores (1870 y 1940). Están las grandes libertades como el respeto individual, las de expresión y de religión, la igualdad ante la ley, la de asociación, de la reunión, y amplios derechos como el de juicio previo imparcial y, en general, aquel acordado a todos los ciudadanos a la misma protección de las leyes.

La Constitución establece que las leyes deben ajustarse a principios morales, definidos ampliamente. Lo cual hace obligatoria y perentoria la suma de revisión y vigilancia en la legislación, en los textos legales y las disposiciones gubernamentales, hasta alcanzar las sentencias judiciales. Lo cual no autorizaría, empero, a suponer que la justicia de los jueces decide casos sin considerar a las leyes promulgadas y a los antecedentes. El respeto a la ley ha creado una garantía de estabilidad de las mismas y la uniformidad de criterio en los fallos ha valorizado y otorgado fuerza fundamental al sistema judicial. La mayor importancia en la actitud de un juez, a veces, ante la ley o ante la índole del pensamiento "justicia” y la suma de rectitud, 
veracidad y comprensión requeridos, serán los imperativos para declarar la inanidad de lo que formalmente es ley, pero que no es por su contenido. La disposición oficial es acusar la controversia legítima (cuando la hay) con la justicia.

Nuestro sistema jurídico está fuertemente imbuido del formalismo legal, lo cual no es óbice para que las causas de revisión judicial de la constitucionalidad de las leyes abunden. Las limitaciones del sistema, caracterizados por la causa particular necesaria y sus consecuencias reducidas importan mucho, pues indican siempre la existencia de un problema constitucional a esclarecer. Idealmente, una mayor amplitud de soluciones sentaría bases interesantes, pero sino se precautelan, además, pueden dar lugar a funestos abusos. No obstante da Constitución debe ser amplia y sin rigideces en este tiempo de libertades para su mejor adaptación y aplicabilidad.

Antiguamente, en las proclamas de ciertos jueces del siglo XVII, sentáronse bases aproximadas a la teoría de Derecho Natural racional, de un derecho común ideal tipo Ilustración adaptado a nuestras circunstancias y a nuestra naturaleza social. Estos principios de derecho común se han extendido a lo largo de nuestra evolución y tomaron mas clara imágen en las constituciones. Cobraron mayor fuerza en la era de las transformaciones jurídicas al punto de asumir una relativa legitimidad natural, siempre afectados por un criterio de bien natural no tomista, que busca el uso de la ley para impedir en cada época el desenfreno de los males individuales y colectivos.

Las instituciones jurídicas han gozado del influjo teórico de la ley natural por múltiples razones, cuando los jueces eran seleccionados entre hombres versados autorizadamente en el estudio del Derecho o poseían altas tradiciones personales religiosas o de servicios públicos. A travez de la Colonia y el Siglo XIX se citan a integérrimos jueces y "hombres buenos" al pensar y decir del Presidente Carlos Antonio López. La dignidad de "Juez" es honrosa y singular. Empero, mucho había de influir la política y otros factores ligados a la educación, la cultura y la economía para llegar a épocas de la magistratura en que confusamente y equívocamente sería convertida en un servicio civil limitado o en un instrumento de despotismos.

Desde 1870, empero, las leyes han marcado el carácter singular de nuestra judicatura, al instituírsela como una de las ramas independientes del gobierno, con los poderes correspondientes, categoría y dignidad similares a los del Parlamento y del Poder Ejecutivo. No deciden nuestros Tribunales problemas políticos ligados al campo moral o jurídico privado. Tal vez, casos ejemplificadores de controversias político-morales, político-administrativas o político-constitucionales no faltan en nuestro medio que, transformados en problemas jurídicos han requerido decisiones judiciales. $Y$ en lo constitucional expresamente, hállase solamente la solución de la controversia de la constitucionalidad, en cada caso particular, en la cima del Poder Judicial. El caso frecuente es el, de la tierra y los mejores derechos a veces hollados o despojados por políticos ú hombres fuertes o sistemas poderosos. El drama de nuestro tiempo se ha extendido a este campo de la judicatura. Los casos o problemas similares que llegan a los tribunales son numerosos, ya sea porque son "casos" no contemplados por la ley o porque los textos legales no son claros o son susceptibles de interpretaciones diversas. Si hay un alto interés moral, el juez tiene un poder superior para resolver, no depende de otros hombres y solo se supedita a Dios y al Derecho.

El siglo $\mathrm{XX}$ en sus comienzos se caracterizó por la aceptación cada vez mas acentuada de que una ley moral superior ha de guiar las decisiones judiciales mediante una ajustada comprensión de las leyes. Los derechos naturales inmutables 
eran respetados con rigor desda las últimas décadas del siglo XIX por los tribunales. Pero, si algunos se respetaban por que estaban implícitamente contenidos en la Constitución, no era óbice para que la legislación admitiera reformas limitativas a derechos privados absolutos. La Corte no anuló las decisiones legislativas sobre regímenes de la tierra, el trabajo, salarios, impuestos y muchas otras leyes de bienestar social siempre y cuando ellas no se apartaban de la fuente constitucional. Es confusa la relación de la doctrina de los derechos naturales inmutables con la de la supremacía de la ley moral, tal como se las observó en nuestro incipiente derecho independiente, en le siglo XIX. Si bien se las amalgamó, sus diferencias fueron suficientes para negarles una validez suprema y excluyente: la existencia de normas y conceptos fijos y, la aplicación de una mayor uniformidad en las decisiones. Este auge, diríamos, de la "teoría de los derechos naturales" podía conducirnos a un sistema de estricta adhesión a los precedentes judiciales, como ocurrió en otras latitudes.

Módulos de justicia, amplios y flexibles, indicaban la línea de la "supremacía de la ley moral". Estos ayudaron a dar mayor desarrollo al pensamiento jurídico. La "equidad" y la "estricta justicia" tuvieron coincidencias, hasta formalizar un sistema suficiente en las leyes escritas de la era de la codificación.

El razonamiento mecánico y el razonamiento lógico caracterizaron al derecho. Es muy conocido el axioma de que "la ley es la ley", incorporado como principio. El gran intento sería el de crear un sistema suficiente y autónomo, cosa que jamás se hizo. El aislamiento de nuestro derecho se mantuvo por décadas, hasta cubrir el primer cuarto del siglo XX. La palpitante realidad del tiempo, con las nuevas corrientes reivindicadoras de las teorías puras del derecho y del Derecho Libre, en sus múltiples manifestaciones, señalaban la necesaria asequibilidad del Derecho a los cambios sociales, económicos y políticos. Nuestro Derecho estaba en su etapa de clasificación y sistematización. Los textos poseían características orgánicas, ya que en el área privada, tenían adoptadas unas mismas o similares fuentes.

Asuntos de derecho público fueron reales preocupaciones en nuestro siglo, cuando se emprendían tareas de análisis. La filosofía jurídica positivista marcaba su carácter peculiar en todos los aspectos del Derecho, desde el formalista legal hasta el sistemático de las normas.

Los derechos naturales inmutables no imponían entretanto limitaciones a los Parlamentos. La filosofía jurídica positivista jugó un papel muy intenso desde las dos últimas décadas del siglo XIX y las normas legales ejercieron notable dependencia. Nuestro positivismo legal ha dado probada importancia a la función del Estado como fuente de derecho. Esto ha sido efecto de la confusión creada por el concepto político de que "estado" es "gobierno", pues no se ha podido negar que, de contínuo, se ha propendido a considerar el proceso político, desde un punto de vista unitario, como una influencia recíproca y conflictiva entre los partidos políticos, una acción de la opinión pública menos intensa y clara y el poder estatal en conflicto, de intensa incidencia en las ramas legislativa, ejecutiva y judicial.

La teoría legal positivista que consideramos, es el derecho como un conjunto de reglas que deben aplicarse lógica y racionalmente a los casos, mediante $\mathrm{y}$, a travez de las leyes. La justicia abstracta ha sido marginada lamentablemente por las leyes encerradas en las rigurosas sistematizaciones creadas por el Parlamento. Este ha dejado muchas veces - es la historia de nuestras legislaturas - de guiarse por consideraciones morales. No puede dudarse tampoco, que la teoría positivista tuvo su plena aceptación, tanto más que la competencia limitada atribuida al juez debía 
ser, en cuanto se refiere a lo moral y a lo económico, suficientemente reducida de modo a no impedir que el pueblo por medio de su voz mayoritaria pueda decidir sobre su derecho mediante la fuerza de la ley.

El positivismo legalista ha contribuido a una mayor y efectiva vigencia e interpretación de las normas legales, Desde la década del 70, en el siglo anterior, su mérito principal fué que dió al derecho paraguayo un gran estímulo para la organicidad y la sistematización. Nuestra doctrina jurídica tomó mas definidos lineamientos mediante una codificación amplia y completa del derecho al modo europeo. La última década del siglo XIX y el primer cuarto del XX dieron impulsos más sistemáticos a nuestro derecho y una apertura a la revisión de doctrinas anacrónicas.

El año de 1940 fué significativo, pues con la Constitución promulgada ese año, se procedió a la formulación de otras reglas de derecho, no solamente en el campo del derecho privado sino tambien en el derecho público. Será necesario, empero, analizar los conceptos contenidos en muchas de sus cláusulas para conocer e interpretar los principios en que se han inspirado. Igual ha de ocurrir con la Constitución de 1967, cuyas pautas doctrinales contienen muchos de los principios y reglas de la anterior carta política. Lo más árduo ha de ser lo relacionado con el derecho privado, al determinar necesariamente las contradicciones.

Nuestro derecho ha registrado importantes progresos: los procedimientos civil, comercial, penal y laboral contienen fórmulas modernas sin los anacronismos de las reglas del antiguo derecho español. Sin embargo, requieren reformas, especialmente los tres primeros. Así tambien los códigos procesal penal militar, tanto como el propio penal castrense, elaborados en el decenio del 80, siglo XIX, adolecen de defectos. Los Códigos del Trabajo, el Aduanero, el Aeronáutico, son altas expresiones de progreso en la codificación. Así y todo, la adopción de los códigos de fondo y de forma fueron acontecimientos de gran relieve en la vida de nuestro derecho. Desde hace varios años se efectúan estudios de nuevos proyectos, trabajos de revisión y modificaciones sustanciales, para simplificar y racionalizar el sistema.

Nuestro derecho ha avanzado tanto en los tiempos finiseculares como en las épocas de transformaciones sociales y políticas que ha sufrido el mundo y el país en este siglo. Sigue desarrollándose y se caracteriza por metas buscadas de verdad, seguridad y uniformidad. El progreso del derecho paraguayo no ha excluído a variadas y distintas filosofías del derecho, pues se han notado desde hace poco menos de un siglo algunos atisbos de formalismos, logicismos $\mathrm{u}$ otras escuelas. Empero, todo indica que las ideas positivistas han sido las impulsoras de las reformas y de la recepción de derechos foráneos.

No hubo controversia entre teorías positivistas y el derecho natural en nuestro campo jurídico. Las leyes formales han dominado el pensamiento jurídico hasta producir una real postura a una evolución abierta a lo nuevo pues, importantes avances intelectuales registrados más adelante dejaron impresos sus registros en nuestras instituciones jurídicas al compás de acontecimientos internos desarrollados en los campos sociales, económicos y políticos en el segundo cuarto del siglo XX.

Creo que las décadas del 20 al 40 del siglo actual, para nuestro pensamiento jurídico ha sido de intensa revisión, preparada y luego definida hacia reformas, adaptaciones o adopciones que se polarizarían en la interpretación de las normas legales conforme a las necesidades y consecuencias sociales de las mismas. Una idea de "solidaridad" y pleno objetivismo del Derecho fueron puntos de partida para una aguda crítica a la ley como fuente única del derecho que carecería de justificación. Críticas al estatismo excluyente y al legalismo absorvente, se extendieron a la luz de interpre- 
taciones relativas a las anunciadas transformaciones del Derecho Público y del Derecho Privado, singularmente, en lo que cuenta con la seguridad, la libertad, la propiedad y su función.

Necesariamente, el derecho ha de considerarse tal cual es el espíritu de la Constitución del año de 1940, como un instrumento del cambio social, de la "mecánica social". Del derecho público, entonces, partieron las fórmulas sistematizadas y mejor decantadas, a travez de veinte años de controversias e inquietas manifestaciones del cambio político y social.

Durante esta segunda mitad del siglo, se ha visto el desarrollo de una oposición constante al formalismo y al conceptualismo legal. Los hechos sociales y políticos son productos contínuos e incesantes de la falta de relación entre lo que constituyen los conceptos y las normas vigentes y las realidades de la vida social. Hasta hoy se vive bajo el imperio, empero, de lo que solo señalan esas normas aparte de los efectos y resultados que podrían tener y, por consiguiente, sin tenerlas en consideración en ningún momento. La fuerza de los acontecimientos ha demostrado que la teoría jurídica no había de ser ya una formulación abstracta, ignorando la realidad social. Un acuerdo equilibrado de hombres e intereses comunes, que podrían dividirse en grupos limitados, ajustados razonablemente y determinados a seguir los intereses de la sociedad y la felicidad del pueblo, se requiere en este tiempo.

Siempre en el período ya indicado, otras ideas primaron que pueden ser calificadas e incluidas en escuelas filosóficas, sujetas a las realidades sociales, a travez de actitudes en el derecho público y, mas contundentemente, en el orden del derecho administrativo, en el nuevo derecho del trabajo, siempre ya en derecho positivo. Son aspectos del "realismo legal", en el cual los factores sociales, económicos, sicológicos y políticos juegan principal papel como las causas profundas que determinan el proceso de la creación de la ley y sus consecuencias sociales. Y yendo mas lejos en la interpretación de un estadio, quienes intuitivamente abrazaron en una época estas fórmulas como causas íntimas, fueron realistas legales, sostenedores de que las reglas de derecho constituyen declaraciones generales de las normas, cuyas fuentes no están en el derecho sino en órganos originales como costumbres, modos de ver, tradiciones, criterios, prejuicios, simpatías, adhesiones, etc.

Sería posible, tal vez, considerar a la jurisprudencia sociológica y al realismo legal como módulos que desempeñan un papel señalado en las reformas estructurales del Estado, y las sociales y económicas de los decenios de 1930 y 1940 inclusive. Nuestra filosofía variada y distinta en muchos casos, hizo posible que se eliminaran durante ese período numerosas y antiguas reglas vigentes, pero ya inaceptables. Los mitos y ciertas ficciones, algunos dificilmente transformados en categorías convencionales, fueron simplemente excluidos. El hecho mas señalado, fué el de una mayor autoridad estatal y en ella un fortalecimiento de la idea de la "administración", medio mejor para resolver con celeridad y responsablemente los problemas sociales, económicos y políticos, fuera del ámbito jurídico público o privado. El punto de vista era el de una vigencia, tal vez esencial de la ley, como instrumento de la regulación socio-económica. La categoría de la administración pública fué elevándose hasta tomar los contornos de una estructura con medios mas eficientes que cualquier otro poder o funcionario. Los problemas sociales y sus secuelas conflictuales, fueron concentrados en el campo competente del Estado (llámese Gobierno) el cual, a su vez, fue creciendo en poder, eficiencia y ejecutividad. 
Los conflictos sociales, sin ser numerosos y frecuentes, experimentaron los efectos de ideologías político-sociales y de modernas filosofías jurídicas a travez de la codificación y han ejercido influencia en el proceso judicial, pues el énfasis puesto en la política social ha sido en orden a que las reglas y sentencias serían orientadas hacia la expansión de los fundamentos adecuados para la solución socialmente justas de las causas.

La guerra del Chaco, librada con Bolivia (1932-1935), abrió nuevos campos, pese a la presión que ejercieron en un breve período posterior e inmediato elementos políticos y administrativos a la sombra de leyes nuevas. Fué una época difícil y dramática en que un sistema de poder discrecional primó agudamente y marcó un periódo de mediatización del derecho y una centralización administrativa excesivamente confusa.

No se puede dudar, empero, que con la guerra se inauguró una época de revisión y surgieron nuevos valores sociales en el Paraguay. Lo legal había ejercido una influencia fría y escéptica, fruto del realismo legalista. La autoridad política tenía fuerza para constreñir a las formas legales, lo cual daba visos totalitarios a decisiones judiciales basadas en interpretaciones inspiradas en ideologías nacionalsocialistas.

No se acusaron, empero, resurgimientos de otras teorías y menos aún la vuelta de doctrinas basadas en la "ley superior". Pausadamente sí, se escucharon voces poniendo énfasis a favor del derecho natural y su lógico necesario afianzamiento. Las libertades civiles, el bienestar social y económico, la libertad de expresión y otras garantías diseminadas en los textos constitucionales y decisiones legislativas y administrativas, fueron un constante acicate por el mejor logro de su observancia. Mucha insistencia se puso durante los últimos treinta años en una aplicación racional de los conceptos jurídicos y de la plena vigencia del Derecho, mediante una salvaguarda mayor de las instituciones.

Han interesado en este tiempo, y se asiste así a un renacer pues constituye una caudalosa corriente, los estudios jurídicos en el orden del derecho privado, tanto más que nuestro derecho positivo ha iniciado la revisión de la codificación vigente. En materia de Derecho Público, dos Constituciones (1940 y 1967) han dado la tónica de una vasta reforma del Estado. En ambas, no están excluidos principios tradicionales de derecho natural y tampoco se han omitido concepciones positivistas. En realidad, todo el clima jurídico no está precisado por teoría predominante alguna, pues a veces se registran hasta fluctuaciones, inseguridad o confusión. Todo esto sería causa y razón de establecer que, sino hay predominio de una determinada teoría jurídica, las influencias y direcciones son diversas y hasta divergentes o antinómicas, de numerosas filosofías jurídicas.

La historia filosófica de nuestras instituciones jurídicas es multiforme y plural. Un soplo poderoso en todo el desarrollo jurídico de la comunidad paraguaya lo constituye la historia, y ella le ha dado su sello peculiar, su espíritu y su carácter. La teoría jurídica gencral, impresa en diversas doctrinas de derecho ostenta sustancias propias provenientes de nuestro inquieto pasado y cuenta con valiosos elementos para un porvenir mas firme y promisor.

Nuestro sello peculiarísimo está en el derecho natural, el positivismo legal y el formalismo, y han sido elementos jusfilosóficos útiles el espíritu historicista en la jurisprudencia histórica, el tomismo y hasta no hace mucho el Kelsenismo. La tendencia a buscas direcciones en los fallos ha sido, al igual, intensa. Pero, se ha visto siempre limitada al campo de las sentencias de los jueces y no al del estudio 
y desarrollo de la filosofía del derecho. En nuestros últimos decenios, se ha visto acoger muchas esencias de los propios hechos políticos, económicos y sociales que, se han incorporado al pensamiento jurídico y a leyes matrices como las Constituciones de 1940 y de 1967.

En este marco, se desarrollan estudios jurídicos que más exploran campos de la ley y nó del propio filosofar. Hay influyos de teorías kantianas, marxistas, stanlerianas, kelsenistas en los doctrinaristas jurídicos. No es de sorprender que sea muy sutil el aprovechamiento de una protección de los intereses jurídicos o una ajustada adopción de lo que es una pura reflexión sobre la validez del Derecho, tomando como punto de partida al hombre mismo y la consideración y problemática de su participación en la comunidad jurídica. El tiempo ha sido una incitación constante en nuestra época a buscar eficaces respuestas formativas a tantas cuestiones, "ejemplos", y hasta "datos" en lo jurídico-positivo.

A la inspiración del racionalismo o el empirismo, no faltaron juristas y jueces, en dar buenas cosechas; el idealismo fue un estímulo y, lo es hoy bajo nuevos ropajes contemporáneos; han predominado individualistas y positivistas. El moralismo, el realismo tienen buena porción en el acerbo cultural jurídico, tanto como no han de faltar atisbos de influencias ideológicas, tales como de un socialismo, a veces avanzado, bajo las fórmulas de un marxismo no confesado.

La ciencia jurídica no ha sido estudiada con suficiente profundidad sino en contadas oportunidades. Mas ha interesado el Derecho como experiencia realizada, pensando en él en forma de intereses, garantías, pretensiones y demandas. $\mathrm{Ha}$ sido y es de interés, el estudio del orden jurídico, y no la investigación, por ejemplo, de la naturaleza o el fin del Derecho. Todo esto ha sido, pues, índice de un contínuo desplazamiento en dirección al esclarecimiento del ordenamiento jurídico, lo cual significa que éste es el proceso elegido de la realización del Derecho. 